\title{
General Psychiatry Case report of a patient with suspected COVID-19 with depression and fever in an epidemic stress environment
}

To cite: Fu R, Zhang Y. Case report of a patient with suspected COVID-19 with depression and fever in an epidemic stress environment. General Psychiatry 2020;33:e100218. doi:10.1136/ gpsych-2020-100218

Received 05 March 2020 Revised 14 April 2020 Accepted 16 April 2020
Check for updates

(C) Author(s) (or their employer(s)) 2020. Re-use permitted under CC BY-NC. No commercial re-use. See rights and permissions. Published by BMJ.

${ }^{1}$ Department of Mental IIIness and Insomnia, Jingmen Stomatological Hospital (Jingmen Mental Health Center), Jingmen, Hubei Province, China

${ }^{2}$ Department of Anorectal Surgery, Second People's Hospital of Jingmen, Jingmen, China

Correspondence to

Yueqin Zhang;

190686586@qq.com

\section{ABSTRACT}

During the COVID-19 pandemic, the number of suspected cases, confirmed cases and those who passed away from the virus has been reported in major media and the internet, and has caused a high degree of tension. In addition, people's outdoor activities have been limited, making it more difficult to find outlets for releasing stress. Under this situation, some people began to experience emotions of anxiety and depression. This article reports a case of depression with fever caused by the stress tension of the pandemic. The patient was highly suspected to have contracted COVID-19. The reported patient, who had a history of depression and had been to Wuhan to attend an exam, showed obvious pre-exam anxiety under the epidemic situation, which gradually increased the patient's pressure and then caused some adverse symptoms, such as insomnia, anxiety, sweating and a reoccurrent fever. Local community authorities paid close attention to him and later sent him to a general hospital in Jingmen for quarantine and treatment, as he was suspected of having COVID-19. After being hospitalised for half a month, he was ruled out from having 'COVID-19' and was cured of depression and discharged from the hospital. From this case, we can realise that, under the situation of the epidemic, people are easily prone to insomnia, anxiety and even depression. As clinicians in general hospitals, especially when encountering large emergencies, we must carefully inquire about the patient's medical history while strengthening our understanding of psychiatric knowledge to improve the recognition rate for depression.

\section{INTRODUCTION}

At the end of 2019, the 'novel coronavirus pneumonia' ravaged the land of China. This disease shows high rates of infection, incidence and mortality, to which the public population is susceptible. ${ }^{12}$ It spread rapidly across the country within a short time and brought a considerable negative impact on the lives and economy of the Chinese people. In order to prevent the epidemic from spreading, the Chinese government made a wise and decisive move to close the city of Wuhan, which played a vital role in the future victory over the 'war epidemic'. Taking the epidemic very seriously, the government upgraded the epidemic to a wartime level emergency. Novel coronavirus pneumonia, an acute infectious pneumonia, was named COVID-19. The main clinical manifestations of COVID-19 in China were fever, fatigue dry cough, and a history of being in Wuhan 14 days before the onset of the disease. The outbreak of the disease in the beginning occurred in Wuhan, Hubei Province, and the surrounding cities of Wuhan. ${ }^{34}$ During that time, the high numbers of people reporting a fever attracted great attention. Under this situation, some people began to experience emotions of anxiety and depression. ${ }^{3}$ Here, we try to distinguish between reoccurrent fever from anxiety/depression induced by epidemic situations and the suspected novel coronavirus pneumonia through the example of this case.

\section{Case history}

The patient, male and 18 years old, showed reoccurrent sweating, fever, cough and fatigue for 1 month, having a history of being in Wuhan for an exam a month ago and then returning to Jingmen 2 days later. Community authorities checked his body temperature, showing $37.8^{\circ} \mathrm{C}$, and realised that the patient had reoccurrent fever and cough for more than a month, and had been to Wuhan in the past month. This attracted much attention and he was sent to an infectious disease department of a general hospital in Jingmen to be hospitalised and was isolated for suspected COVID-19. ${ }^{5}$ The results of physical examination were as follows: isometrical pupils sensitive to light reflection, no rigidity in the neck, body temperature of $37.8^{\circ} \mathrm{C}$, heart rate of 110 beats/min, respiratory rate of 20 breaths $/ \mathrm{min}$ and blood pressure of $110 / 70 \mathrm{kPa}$. Chest CT showed a few fibrous foci in the right middle lobe. Nucleic acid test of novel coronavirus was negative on admission day and on the third day. Tests of nine respiratory virus, influenza $\mathrm{A}$ and $\mathrm{B}$ virus antigens showed negative. Mycobacterium tuberculosis antibodies were negative. Thirteen 
items of extractable nuclear antigen antibody were negative. Ten items of toxoplasma, others, Rubella virus, Cytomegalovirus, erpes virus were negative. No abnormalities were found in blood, urine routine, liver and kidney function, myocardial enzyme spectrum, thyroid function, $\mathrm{C}$ reactive protein, equivalent series resistance, hepatitis B, hepatitis C, HIV antibody and treponema pallidum antibody. The patient's temperature did not improve for 5 days after admission. All blood biochemical and auxiliary examinations were normal. Chief complaints from the patient were as follows: when going to Wuhan to take an important exam a month ago, he felt more stressed than before and was always worried about failing the exam; during that time, when COVID-19 was outbreaking, he developed symptoms such as nervousness, sweating, fever, insomnia and dizziness, which made him consider himself as suffering from COVID-19. The patient's mood was low, pessimistic and negative. He reported sleeping poorly at night, sleeping for only about 3 hours a night, being restless in the ward and being nervous during the day. He often sweated after having body tension, and then the body temperature dropped; after experiencing a cold irritation, his body temperature rose again, between $37.5^{\circ} \mathrm{C}$ and $38^{\circ} \mathrm{C}$. His family members reported that he showed a depressed mood for more than a month and had a 6-year history of depression. After ruling out any physical illnesses causing the fever, psychiatrists carefully inquired interviewed the patient and his family members and considered that (1) although the patient had been to Wuhan a month ago, he did not have any close contact with people in Wuhan. He was driven back and forth to Wuhan by his father (2) there were no clinical indicators of 'COVID-19' in all auxiliary examinations in the patient (twice nucleic acid test was negative, and no ground-glass CT was seen in the lung), and the close contacts of the patient (his parents and grandpa) did not have fever, cough and other discomforts (and the father, who stayed with him during the hospitalisation, also underwent a novel coronary pneumonia nucleic acid test, which showed negative) $;^{6}$ given that the patient had a history of depression for 6 years and was hospitalised in our hospital three times due to the reoccurrence of depression, was particularly anxious during each episode, and then sweated followed by an increased body temperature; when the symptoms of depression and anxiety improved, his body temperature returned to normal. Considering these aforementioned facts, we thought that the fever symptom was caused by repeatedly catching cold, after a sweat due to anxiety. Hence, he was immediately transferred to the psychology department because of depression and, before the exclusion of COVID-19, underwent isolation treatment from medical staff who were under secondary protection. The patient was admitted to the hospital with complaining of 'anxiety, depressed mood, slow thinking, self-blame, reoccurrent fever, cough, fatigue for 1 month, and a 6 year history of depression'. The results of psychological examination were as follows: clear consciousness; complete orientation; appropriate emotional response; passive contact; negative pessimism; slow thinking; selfblame and self-incrimination; repeated complaints of infection by 'novel coronavirus', which had encumbered his family members; depressed mood; anxiety; poverty of speech; and good insight. Laboratory examinations and blood biochemical examination showed no abnormalities. The Hamilton Depression Scale ${ }^{7}$ score was 26; the Emotional Self-rating Scale/Depression-Anxiety-Stress Scale $21^{8}$ showed a depression score of 25 , an anxiety score of 16 and a stress score of 30 . After admission into the hospital, he was treated with venlafaxine sustainedrelease tablets $(75 \mathrm{mg} /$ tablet, oral administration, two times per day in the morning and midday), olanzapine tablets $(2.5 \mathrm{mg}$ /tablet, once a day in the midday, oral anxiolytic) and olanzapine tablets $(5 \mathrm{mg} /$ tablet, oral, once every night). After 3 days, the patient's night-time sleep improved significantly with 7 hours of deep sleep every night; anxiety during the day significantly improved; the symptom of sweating in the patient disappeared; and the body temperature dropped to between $36.5^{\circ} \mathrm{C}$ and 37 ${ }^{\circ} \mathrm{C}$. The patient's depressive mood significantly improved after 10 days of treatment. The patient smiled when talking and even said that he was in a good mood and was full of hope for his future life. Additionally, he displayed active thinking and showed no anxiety or low self-esteem and pessimistic mood. After being hospitalised for half a month, he was ruled out from having COVID-19 and was cured of depression and discharged from the hospital. After a week, the telephone feedback showed that the patient's mood was stable and that no discomfort such as fever and cough had occurred.

\section{DISCUSSIONS}

Depression, which is characterised by a significant and lasting depressed mood, is a common type of mood disorder. Clinically, it can be seen that the moods of patients with depression are disproportionate to their situations. The depressed moods can range from dejection to sorrow, low self-esteem, depression and even pessimism. The patients may have suicidal attempts or behaviours. The main symptoms are sleep disorder, fatigue, loss of appetite, weight loss, constipation, pain, loss of libido, impotence and amenorrhoea. Depression can also cause disorders in the autonomic nervous system with unexplained physical symptoms, such as fever, night sweats, fatigue, insomnia, weight loss and hand tremor. There were previous reports showing that anxiety symptoms caused fever. ${ }^{9}$ The clinical manifestations of COVID-19 are mainly fever, fatigue and dry cough, and the screening content mainly include the monitoring of fever, dry cough, shortness of breath,etc., and inquiry of epidemiological history.

This case was a patient with depression who was in the maintenance stage of treatment. The depression symptoms reoccurred under the pressure of the COVID-19 epidemic. The patient's fever was the symptom that overlapped with depression/anxiety and COVID-19. 
Coincidentally, the patient with depression in this case also suffered the symptoms of reoccurrent fever, cough and fatigue. It shows that the level of stress can affect metabolism and cause a fever. ${ }^{11}{ }^{11}$ The dual effects of depression and stress led to repeated incidence of fever in this case. The patient also had a history of recent travel in Wuhan. In that sensitive period, everyone with fever and a history of recent travel in Wuhan was easily associated with COVID-19. After being discovered by the community, he attracted great attention and was then immediately sent to a general hospital. Under that emergency, his family members forgot to report his history and symptoms of depression to the doctor in charge; in addition, the general practitioners he was seen by in China did not know enough about depression. ${ }^{12}$ Thus, the patient was misdiagnosed as a suspected COVID-19 case. After diagnosis by a psychiatric specialist, the patient was treated with antidepressant and anxiolytic drugs. With the improvement of his depression symptoms, the patient's other symptoms, including fever, cough and other symptoms, disappeared. Moreover, the patient's various auxiliary tests did not suggest the possibility of COVID-19. The patient was ruled out as having COVID-19 and was diagnosed with depression.

From this case, we can obtain some inspiration. In the midst of the COVID-19 pandemic, people are prone to insomnia, anxiety and even depression. ${ }^{13}$ Patients with a history of depression have a poorer ability to resist stress than others and are more likely to experience a relapse of anxiety and depression, and deserve more social attention. Before and after similar outbreaks and major public events, community health service stations and psychiatric professionals should improve preventative measures. This includes telephone follow-ups, improvements in psychological counselling and proactive adjustment of medications, if needed. These measures can all help to nip the reoccurrence of depressive symptoms in the bud. As clinicians, especially on encountering large crises, we must carefully inquire about the medical history and strengthen multidisciplinary consultation while improving knowledge of psychiatric conditions amongst non-psychiatric staff in order to improve the detection rate for depression in general hospitals.
Contributors RF: collection of article cases and main analysis writing. YZ: literature search and article translation proof reading.

Funding The authors have not declared a specific grant for this research from any funding agency in the public, commercial or not-for-profit sectors.

Competing interests None declared.

Patient consent for publication Obtained.

Provenance and peer review Not commissioned; externally peer reviewed.

Open access This is an open access article distributed in accordance with the Creative Commons Attribution Non Commercial (CC BY-NC 4.0) license, which permits others to distribute, remix, adapt, build upon this work non-commercially, and license their derivative works on different terms, provided the original work is properly cited, appropriate credit is given, any changes made indicated, and the use is non-commercial. See: http://creativecommons.org/licenses/by-nc/4.0/.

\section{REFERENCES}

1 Bogoch II, Watts A, Thomas-Bachli A, et al. Potential for global spread of a novel coronavirus from China. J Travel Med 2020;27.

2 Li Q, Guan X, Wu P, et al. Early transmission dynamics in Wuhan, China, of novel Coronavirus-Infected pneumonia. N Engl J Med Overseas Ed 2020;382:1199-207.

3 Lei $\mathrm{C}$, XueBing H. Suggestions on public mental health during the COVID-19 epidemic. Chinese Mental Health, 2020. http://kns.cnki. net/Kcms/detail/11.1873.r.20200310.1528.068.html

4 Xiaoke XU, WENcheng. The geographical destination distribution and effect of OutflowPopulation of Wuhan when the outbreak of the 2019-nCoV pneumonia. Available: http://kns.cnki.net/kcms/detail/51. 1207.T.20200213.2002.002.html

5 Holshue ML, DeBolt C, Lindquist S, et al. First case of 2019 novel coronavirus in the United States. N Engl J Med 2020;382:929-36.

6 Working Group of Novel Coronavirus Pneumonia, Zhongshan Hospital Zhongshan Hospital, Fudan University. Guideline for the diagnosis and clinical management of suspected novel coronavirus pneumonia in Zhongshan Hospital,Fudan University(2020 v.1). J Chin Clin Med.

7 Zimmerman M, Thompson JS, Diehl JM, et al. Is the DSM-5 anxious distress specifier interview a valid measure of anxiety in patients with generalized anxiety disorder: a comparison to the Hamilton anxiety scale. Psychiatry Res 2020;286:112859.

8 Dohyun Let.al. The convergent, discriminant, and nomological validity of the depression anxiety stress Scales-21 (DASS-21). J Affect Disord 2019;259.

9 Zhu Y, Yueyun ZHU. Diagnosis and treatment of rash fever with anxiety. Shanghai Arch Psychiatry 2017;29:247-249.

10 Hayley S, Merali Z, Anisman H, et al. Stress and cytokine-elicited neuroendocrine and neurotransmitter sensitization: implications for depressive illness. Stress 2003;6:19-32.

11 Kataoka N, Shima Y, Nakajima K, et al. A central master driver of psychosocial stress responses in the rat. Science 2020;367:1105-12.

12 Wang Y, Murray AM, Toussaint A-K, et al. Why is the recognition rate of psychological distress under-estimated in general hospitals? A cross-sectional observational study in China. Medicine 2019;98:e16274.

13 Yi W, Jun-ling G. The relationship between media exposure and mental health problems during COVID-19 outbreak. Fudan University Journal of Medical Sciences, 2020. http://kns.cnki.net/kcms/detail/ 31.1885.R.20200307.1736.008.html

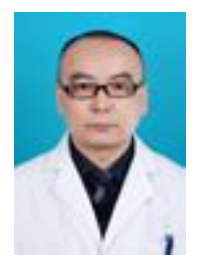

Rui Fu graduated from Tongji Medical University of Hubei Province in 1999. He is currently working as vice director of the sleep disorders clinic at the Hubei Jingmen Stomatological Hospital (Jingmen Mental Health Center). His main research interests include applied physiological treatment (cold stimulation) for insomnia, anxiety, depression and early-onset schizophrenia. 